\title{
Linguagem ficcional e carnavalização: aspectos dialógicos e ideológicos do reflexo e da refração social do filme $O$ primeiro mentiroso
}

\author{
Fictional language and carnivalization: dialogic and \\ ideological aspects of the social reflection and refraction in the film \\ The Invention of Lying
}

Andre Cordeiro dos Santos*

rdnao@hotmail.com

Universidade Federal de Alagoas

RESUMO: Tomando parte dos estudos da linguagem ficcional e de como esta reflete e refrata a realidade, neste artigo, propomos estudar os modos pelos quais 0 filme O primeiro mentiroso, de Ricky Gervais e Matthew Robinson, reflete e refrata as relações sociais, por meio do discurso sobre a mentira. Para tanto, partimos dos escritos do Círculo de Bakhtin e procedemos à análise de excertos-dizeres do filme - característicos dos momentos nos quais o discurso sobre a mentira se evidencia. Acreditamos ser importante analisar a construção ficcional de realidades outras para evidenciar as relações dialógicas entre dizeres e, por conseguinte, evidenciar também que a linguagem é social em todas as suas esferas de atividade. Por meio da análise foi possível observar que o filme, por ser um acontecimento estético, tende a carnavalizar as relações sociais e, por meio desse processo de carnavalização, diferentes discursos sobre a mentira se evidenciam.

PALAVRAS-CHAVE: Discurso ficcional. Marcas dialógicas-ideológicas. Carnavalização. O primeiro mentiroso.

ABSTRACT: Based on fictional language studies and how language reflect and refract reality, in this article, we intend to study the forms in which Ricky Gervais and Mathew Robinson's film The Invention of Lying reflects and refracts social relationships through speeches about lying. Therefore, starting from the writings of the Bakhtin Circle, we then analyze oral excerpts from the film - the ones which are characteristic of moments when speeches about lying become evident. We believe it is important to analyze the fictional construction from other realities to make evident the dialogic relationship between utterances and, consequently, to show that

\footnotetext{
${ }^{*}$ Mestre em Letras-Linguística pela Universidade Federal de Pernambuco e estudante de doutorado Letras e Linguística na Universidade Federal de Alagoas, na linha de Linguística Aplicada; bolsista da CAPES.
} 
language is social in all its spheres of production. Through the analysis it was possible to observe that the film, an aesthetic event, tends to carnivalize social relationships and, through this carnivalization process, different speeches about lying become evident.

KEYWORDS: Fictional discourse. Dialogic and ideological marks. Carnivalization. The Invention of Lying.

\section{Introdução}

A linguagem é, por excelência, ideológica, como defendem os estudiosos do Círculo de Bakhtin ${ }^{1}$ em seus escritos, ao se debruçarem sobre a questão da linguagem e saírem em defesa de uma perspectiva social-marxista de linguagem ${ }^{2}$. Logo, para esses estudiosos, por trás de todo dizer, independentemente da esfera de comunicação na qual esse dizer vire ato, subjaz uma ideologia que dá sustentação ao dizer dito - enunciação - e marca um lugar único ocupado no mundo.

Tomando esse posicionamento como ponto de partida, quando pensamos em todo e qualquer ato de linguagem, precisamos levar em consideração os fios dialógicos-ideológicos ${ }^{3}$ que dão sustentação aos dizeres, pois eles darão indícios para a construção do sentido e evidenciarão um lugar ocupado, assinado, por um sujeito singular, mesmo em práticas de linguagem de natureza ficcional.

A esse respeito cabe ressaltar que, apesar de Volochinov (2013) defender que a palavra na poesia (ou arte, em sentido mais amplo) é da mesma natureza que a palavra na vida, existe, em outro escrito do Círculo, a indicação de que a palavra na vida e a palavra na arte comportam especificidades. De acordo com Bakhtin (2011), existem diferenças entre o acontecimento estético e o acontecimento ético embora não sejam dicotômicos. Essas diferenças dizem respeito, sobretudo, a não coincidência de consciências, ou seja, enquanto no ato estético a consciência do autor não coincide com a consciência da personagem - diferenciação fruto da criação -, no ato ético há o relato de um fato e, nesse caso, autor e personagem estão diante de um valor comum - algo dado. Nas palavras do autor,

\footnotetext{
${ }^{1}$ Grupo de estudiosos russos, composto por Bakhtin, Volóchinov, Medviédev, entre outros.

${ }^{2}$ Tratamos dessa concepção de linguagem na seção seguinte.

${ }^{3}$ Nós nos deteremos a esses fios dialógicos-ideológicos mais adiante.
} 
Um acontecimento estético pode-se realizar-se apenas na presença de dois participantes, pressupõe duas consciências que não coincidem. Quando personagem e autor coincidem ou estão lado a lado diante de um valor comum ou frente a frente com o inimigo, termina o acontecimento estético e começa o acontecimento ético que o substitui (o panfleto, o manifesto, o discurso acusatório, o discurso laudatório, o de agradecimento, o insulto, a confissão relatório, etc) (BAKHTIN, [2011a [1920/30], p. 19-20).

Ou seja, no caso do ato/acontecimento ético, o compromisso com o dado é bem maior que no caso do ato/acontecimento estético, pois este último pode criar "universos" nos quais os fatos sejam tornados excêntricos, rompendo com a ordem e as regras sociais estabelecidas, ainda que apenas momentaneamente.

É importante conhecer essas especificidades acima (principalmente no caso do ato/acontecimento estético); no entanto, essa diferenciação de atos não exime a linguagem ficcional de sua natureza ideológica. O que acontece é que, no caso do acontecimento estético, essa ideologização pode se evidenciar pela criação de um "universo" oposto ao "universo dado" - o que caracteriza a carnavalização (BAKHTIN, 2015). Nesse sentido, achamos importante analisar a construção ficcional de realidades outras - "diversas" da realidade dada - que comporta fios ideológicos, a fim de evidenciar as relações dialógicas entre dizeres e, por conseguinte, evidenciar também que a linguagem é social em todas as duas esferas de atividade.

Partindo dos pensamentos dos estudiosos do Círculo supracitados, e considerando que as obras de ficção materializam ideologias sociais - ainda que sob uma ótica excêntrica -, tomamos uma obra ficcional como corpus de análise e questionamos como esta obra, o filme O primeiro mentiroso, de Ricky Gervais e Matthew Robinson, reflete e refrata as relações sociais. E, buscando responder ao questionamento acima, temos como objetivo identificar como o discurso da mentira é refletido e refratado nesta obra cinematográfica.

Para buscar responder ao questionamento gerador da pesquisa, procedemos a análise de excertos-dizeres do filme $O$ primeiro mentiroso, a partir dos quais pudemos analisar os discursos sobre a mentira que se fazem presentes no filme, refletindo e refratando questões de ordem social. É importante dizer que esses excertos-dizeres foram extraídos da versão em português do filme. Reconhecemos que a mudança de língua do filme ocasiona mudanças ideológicas; no entanto, não nos ateremos a essa questão neste trabalho. Além disso, cabe mencionar que os 
excertos-dizeres foram selecionados dos momentos nos quais o discurso sobre a mentira se evidencia, a fim de analisar a constituição do fenômeno da carnavalização.

Por fim, cabe ainda mencionar que esse trabalho de análise discursiva surgiu a partir das discussões da disciplina Linguística Aplicada II: estudos sobre o sujeito da linguagem - teoria e metodologia, do programa de Pós-Graduação em Letras e Linguística da Universidade Federal de Alagoas, ministrada pela professora doutora Rita de Cássia Souto Maior.

Dito isso, passemos à discussão de aspectos relacionados à concepção de linguagem do Círculo de Bakhtin e a aspectos da construção ficcional do filme.

\section{A linguagem e a criação ficcional}

Pensando que as práticas de linguagem ficcional, que se materializam como acontecimentos/atos estéticos, também são perpassadas por questões de ordem social - ainda que apresentem um compromisso menor com o dado -, trazemos à discussão a concepção social-marxista de linguagem, que considera os reflexos e refrações ${ }^{4}$ das relações sociais, bem como o lugar ocupado pelo sujeito, como determinantes para a construção de sentido, para, assim, posteriormente, procedermos à análise dos dados.

O Círculo de Bakhtin inaugurou, no início do século $X X$, uma discussão bastante singular, no que se refere ao estudo da linguagem. Em um momento histórico-social no qual os estudiosos da área da linguagem eram guiados por questões de ordem linguístico-sistêmica e/ou psíquico-individuais, caracterizando o objetivismo abstrato e subjetivismo idealista/individualista, respectivamente (BAKHTIN/VOLOCHINOV, 2006 [1929]), os estudiosos desse grupo inauguraram uma perspectiva nova, na qual as questões de ordem social ganham espaço, no que se refere aos fenômenos da linguagem.

Essa perspectiva social-marxista, segundo Fanini (2015), estudiosa da obra do Círculo, baseia-se na ideia de que a linguagem é constitutiva do ser social desde suas primeiras instâncias e, consequentemente, a põe como centro organizador das práticas sociais. Por isso, esse entendimento de linguagem tem como base as

\footnotetext{
${ }^{4}$ As noções de reflexão e refração do Círculo de Bakhtin dizem respeito à repetição e à criação do novo (assinado por um sujeito), respectivamente.
} 
seguintes proposições-síntese: o sistema de signos, por si só, não dá conta da realidade dos fenômenos linguísticos; a língua é um fenômeno em processo e esse processo se efetiva pela interação; as leis da evolução da linguística são sociológicas; a criatividade de uma língua está ligada aos valores ideológicos e essa criatividade é originada de uma necessidade social; e a enunciação é puramente social/ideológica (BAKHTIN/VOLOCHINOV, 2006).

A partir da consideração das proposições acima, podemos perceber que essa concepção se caracteriza como essencialmente social-dialógica, ou seja, nela se consideram as questões de ordem social - já que o enunciado comporta uma parte verbal e uma extraverbal (VOLOCHINOV, 2013 [1930] -, e colocam-se os sujeitos da linguagem como elementos fundamentais para a construção do sentido (BAKHTIN, 2010 [1919/20]; 1998 [1934/35]; 2011 [1952/53]; BAKHTIN/ VOLOCHINOV, 2006 [1929]; VOLOCHINOV, 2013 [1930ab]; MEDVIÉDEV, 2012 [1928]).

Assim, quando queremos construir o sentido para um ato de linguagem, precisamos considerar os elementos dialógicos que materializam relações de diálogo no enunciado - elegido como unidade por excelência da interação verbal por Bakhtin/Volochinov (2006) - com os elementos que compõem as instâncias enunciativas. Essas marcas dialógicas, das quais o Círculo fala, podem ser resumidas, segundo Santos (2015), da seguinte forma: a orientação social para o outro; a presença de diferentes vozes sociais que dialogam ou se conflitam; a materialização do enunciado enquanto elo entre os já-ditos e a presunção de respostas; a adequação ao contexto enunciativo, e as marcas valorativas/emotivovolitivas/axiológicas do sujeito em relação ao objeto da enunciação.

A partir da consideração dessas marcas dialógicas-ideológicas, acreditamos que seja possível iniciar a análise dos discursos que se fazem presentes no filme "O primeiro mentiroso". No entanto, para cumprir o objetivo proposto neste artigo, faz-se necessário trazer à discussão, também, a noção de carnavalização, defendida por Bakhtin (2015).

Para a discussão da noção de carnavalização na literatura, Bakhtin (2015) parte do conceito de carnaval. Para o autor (p. 139-140), a noção de carnaval diz respeito ao conjunto de todas as variadas festividades, ritos e formas do tipo carnavalesco, no qual todas as ordens e as regras do cotidiano podem ser invertidas, enquanto este vigora. Para o estudioso, isso ocorre porque as leis, as 
proibições e restrições se revogam durante o carnaval. Ou seja, no carnaval, tudo é permitido, até a inversão das relações sociais, ainda que momentaneamente.

Partindo dessa noção de carnaval, Bakhtin (2015) propõe estudar a influência determinante que o carnaval tem na literatura, especialmente no que se refere aos aspectos do gênero. Desse modo, o autor visou a investigar como as regras sociais eram quebradas e como o excêntrico ganhava espaço no universo da criação que se materializava por meio de atos/acontecimentos estéticos.

Vistas a isso, considerando que a inversão, por um determinado espaço de tempo, da ordem social é uma característica determinante da noção de carnavalização da literatura defendida por Bakhtin (2015), pois esse fenômeno tende a romper momentaneamente com a ordem natural-social das coisas, propomos transpor essa noção para o estudo da criação-ato de natureza ficcional e cinematográfica. No caso deste estudo, especificamente, propomos transpor essa noção para a análise da obra cinematográfica $O$ primeiro mentiroso, nosso objetocorpus de análise, para, assim, observarmos como esse "universo" ficcional reflete e refrata o social, e, como consequência, detectar indícios dos discursos da mentira que se fazem presentes no filme por meio dos seus dizeres.

Pensamos que, por aproximar o sagrado do profano, o elevado do baixo, o grande com o insignificante, o sábio com o tolo, etc. (BAKHTIN, 2015, p. 40), essa noção de carnavalização nos permite compreender como esse ato de suspender a ordem social das coisas coopera para a construção, ou indiciamento, dos discursos da mentira do filme $O$ primeiro mentiroso.

Expostas as noções teóricas que nos servem de base para esse estudo, passamos, a seguir, à apresentação do enredo do filme e, concomitante a isso, analisamos como alguns dizeres-atos do filme materializam relações dialógicoideológicas que apontam para uma carnavalização da ordem social, sobretudo, por meio dos discursos sobre a mentira que os perpassa.

\section{0 primeiro mentiroso: excentricidade e carnavalização do social}

O filme $O$ primeiro mentiroso, de Ricky Gervais e Matthew Robinson, foi produzido pela Warner Bros Picture e pela Radar Pictures, nos Estados Unidos da América, no ano de 2009. Este filme narra a história do primeiro homem a contar uma mentira; ou seja, o filme se detém à suposta história da origem da mentira. No 
mundo criado no filme, de início, a mentira ainda não existia e, portanto, as pessoas só falavam a verdade. No decorrer do filme, a personagem principal, Mark, tem um "estalo de consciência" e, diante de uma situação difícil - ele estava prestes a ser despejado - tem a ideia de, na hora de sacar todo o dinheiro de sua conta, estando o sistema do banco fora do ar, dizer que tinha o valor necessário para pagar o aluguel, oitocentos dólares, quando, na verdade, só tinha trezentos. A partir de então, a personagem passa a ter a capacidade de falar coisas que não são de fato e, com isso, conseguir alguns benefícios para si e para outras personagens, como, por exemplo, sua mãe.

O fato de Mark poder contar mentiras gera grandes consequências no filme, como, por exemplo, após ter inventado uma história sobre como seria o pós-morte para sua mãe, tentando acalmá-la, ele acaba falando que, após a morte, as pessoas iriam para um lugar muito feliz, onde não haveria tristeza e cada pessoa teria uma mansão. Mark torna-se uma espécie de profeta que tem a capacidade de falar com "o homem do céu". Nesse momento, percebemos que o fenômeno da carnavalização (BAKHTIN, 2015) começa a se constituir, pois o fato de Mark ter desenvolvido a capacidade de mentir o torna "um ser superior", capaz de falar com o "homem do céu".

Por meio das mentiras que ele conta no filme, ele consegue seu emprego de volta e um prestígio muito grande, criando histórias que as demais personagens do filme acreditavam ser verdade - já que naquele mundo não existia a mentira. Com suas mentiras, Mark consegue muitas coisas, mas a única coisa que ele não consegue por meio da mentira é o amor de Anna, pois, segundo ele, só valeria à pena se fosse de verdade. Nesse momento, é possível perceber que a superioridade conferida pela capacidade de mentir se desfaz, pois Mark não é capaz de mentir para conseguir o amor dela. Ao dizer que só valeria se fosse de verdade, Mark consegue conquistar o amor de Anna, e os dois terminam juntos, com um filho - filho esse que também consegue mentir, como se a capacidade de mentir fosse algo hereditário.

Ao nosso ver, no desenrolar dessa história, o discurso sobre a mentira se mostra de três formas diferentes, que juntas constituem o fenômeno da carnavalização (BAKHTIN, 2015), por isso optamos por analisar, mesmo que brevemente, esses três momentos de forma separada, por fins didáticos, embora 
saibamos que os três juntos formam um todo, um ato estético (BAKHTIN, 2011a [1920/30]). Passemos, desse modo, à análise do primeiro momento.

2.1 Carnavalização e discurso sobre mentira: primeiro momento - o mundo sem a mentira

Nesse primeiro momento de análise, detemo-nos ao período que compreende do início do filme até o momento que Mark, a personagem principal, tem o "estalo de consciência" e conta a primeira mentira. Essa análise se dará por meio de excertos-dizeres das personagens do filme.

O filme se inicia com a chegada de Mark à casa de Anna para um encontro que os dois haviam combinado, a fim de se conhecerem. Nesse momento do filme, ao abrir a porta para Mark, Anna diz as seguintes falas:

Anna: Oi! [...] Chegou cedo! [...] Tava me masturbando. [...] Tô meio frustrada, no momento. Além de bem deprimida. E pessimista com o nosso encontro. [apontando para ele]

Percebemos que a fala da personagem vem carregada de uma sinceridade perversa - na comparação com as relações sociais atuais -, por meio da qual a personagem Mark fica constrangida. Nesse ponto, podemos perceber que as relações sociais representadas pelo filme, enquanto ato/acontecimento estético (BAKHTIN, 2011a [1920/30]) que são, acabam por estabelecer uma relação discursiva de refração, caracterizada pelo diálogo-conflito (BAKHTIN, 1998 [1934/35]) com a ordem social das coisas.

$\mathrm{Na}$ sequência, quando já estão no restaurante onde se deu o encontro, durante uma conversa com a mãe por telefone, Anna novamente diz coisas com o mesmo teor de sinceridade perversa. Vejamos:

Anna: Não, não é muito atraente! [...] Não, não ganha muito dinheiro! [...] É meio gordinho e também tem um narizinho de batata e parece um sapo assim na região da face.

Fica evidente, mais uma vez, que o filme retrata uma situação que se distancia da ordem social vigente, caracterizando uma relação de diálogo-conflito com a sociedade atual (BAKHTIN, 1998 [1934/35]), pois não é comum, em nome da cordialidade, que as pessoas digam esse tipo de coisa a outras pessoas. $\mathrm{Na}$ 
sociedade atual, há uma questão de ética e moralidade que rege as relações sociais entre sujeitos. Isto acontece porque, sendo os sujeitos constituídos discursivamente, eles apresentam-se como essencialmente ideológicos e, enquanto tal, refletem e refratam comportamentos de outrem (BAKHTIN/VOLOCHINOV, 2006 [1929]).

É importante mencionar que a questão da ética e da moralidade não são questões centrais do filme. Durante todo o filme, há uma ausência de preocupações éticas nas relações entre os sujeitos-personagens. Esta ausência pode ser vista nos seguintes dizeres do colega de trabalho de Mark, diante da demissão deste:

Brad (Colega de Mark): Eu só queria te dizer adeus e que sempre te odiei. [...] Até coloquei gente contra você. [...] Você é péssimo escritor. [...] Você vai ser um fracasso e eu sempre vou ser bem mais sucedido que você em quase tudo na vida. [...] Curte a vida de fracassado!

Essa reação do colega de trabalho é bem diferente do que se esperaria socialmente nessa situação, em razão do senso de humanidade. O esperado seria que o colega, ainda que achasse justa a demissão, mostrasse-se compadecido da situação. Desse modo, mais uma vez, percebemos uma inversão da ordem social das coisas, o que vem apontando para um processo de carnavalização dos atos sociais (BAKHTIN, 2015).

Por fim, nessa primeira parte do filme, antes de Mark contar a primeira mentira, ele tem o seguinte diálogo com a mãe, no abrigo de idosos no qual ela está internada:

Mark: Perdi meu emprego hoje, mãe! Estou nos 40, sozinho e sem perspectiva.

Martha (mãe de Mark): A situação não é melhor para mim aqui. Mas podia ser pior. Poderíamos ser sem-teto.

Mark: Não gostaria de mudar de vida? Não gostaria de ser bemsucedida?

Martha (mãe de Mark): Eu não me acho um fracasso!

Mark: Mas é, mãe, com certeza! Viemos de uma linhagem de fracassados. Não é sua culpa. A senhora é um fracasso.

O diálogo acima mostra-se oposto ao discurso social em relação às mães, pois, numa ideologia social vigente, as relações entre mães e filhos, geralmente, tendem a ser extremamente pautadas no amor e respeito e, por isso, palavras tão duras, como as mostradas no excerto acima, não são comuns a essa relação fraternal - embora possam fazer parte delas. 
A partir das situações e dos dizeres acima, percebemos que a criação desse universo ficcional, por meio de um ato estético (BAKHTIN, 2011a [1920/30]), aponta para uma suspensão do que se espera de uma boa relação entre mãe e filho. Esse modo de retratação-criação de relações sociais, a nosso ver, é característico do que Bakhtin (2015) chamou de carnavalização, pois, na ficção, a ordem social das coisas pode ser suspensa momentaneamente e ajuda na materialização da carnavalização na obra (BAKHTIN, 2015). Desse modo, também percebemos uma relação de diálogo-tensão nos enunciados dessa primeira parte do filme, em relação à realidade (BAKHTIN, 1998; SANTOS, 2015).

Além disso, por meio de passagens como as descritas acima, é possível notar que relações sociais pautadas unicamente na verdade podem não ser a forma mais adequada de um convívio social harmônico. Vistas a isso, por trás dessa primeira parte do filme, há indícios de um discurso da mentira como elemento necessário (e talvez indispensável) para boas e cordiais relações entre indivíduos de uma sociedade.

Outrossim, podemos perceber que, nesse primeiro momento, a personagem principal é caracterizada como um anti-herói, um "bobo". Essa caracterização inicial da personagem principal é essencial para a compreensão do fenômeno da carnavalização na obra como um todo.

Feita a análise dessa primeira parte do filme, passemos à análise da segunda parte, momento a partir do qual Mark conta a primeira mentira.

2.2 Carnavalização e mentira: segundo momento - as primeiras mentiras contadas

Em um segundo momento do filme, o protagonista, diante de uma situação difícil (prestes a ser despejado e precisando sacar todo o seu dinheiro do banco), vê a oportunidade de contar algo que não era de fato. Ele diz à atendente do banco que tinha oitocentos reais em sua conta, quando, na verdade, só tinha trezentos. Surge aí a primeira mentira e, a partir disso, o protagonista começa a ter a malícia (talvez consciência) necessária para contar coisas que não são de fato.

Desse momento em diante, o protagonista começa a usar a mentira como um meio para conseguir conduzir situações de uma forma mais harmônica e, com isso, consegue tirar grandes proveitos. Nesse ponto, o discurso da mentira indiciado no filme é diverso do que se evidenciou na primeira parte. 
Vejamos, por exemplo, o seguinte diálogo, através do qual, usando da capacidade de poder contar mentiras, Mark consegue fazer Frank desistir da ideia de suicídio:

Frank: E aí, Mark, tudo bem?

Mark: Bem! E você, como é que está?

Frank: Muito mal! Eu fiquei acordado a noite toda pesquisando na internet sobre suicídio por asfixia. Acho que é isso que vou fazer hoje. Só pra te avisar, tá?

Mark: Frank?

Frank: O quê?

Mark: Não faça isso!

Frank: Ah, por quê? Sou um ferrado! Ninguém vai ligar mesmo!

Mark: Eu ligo!

Frank: Você é um idiota! Não conta!

Mark: A situação vai melhorar!

Frank: Ah, vai?

Mark: Você vai conhecer alguém. Vai ser feliz.

Frank: Eu não devo me matar?

Mark: É claro que não!

Frank: Tá bom! Eu não devo me matar!

As falas de Mark, no que dizem respeito à melhora de situação para Frank e ao fato de que ele conhecerá alguém, são, na verdade, mentiras contadas pelo protagonista a fim de evitar que Frank cometesse suicídio. Desse modo, a personagem principal, de "bobo", passa a ser detentora de uma superioridade que o torna capaz até de salvar vidas, como é o caso. A mentira o transforma numa espécie de "rei". Percebemos que, a partir desse momento, por meio da relação euoutro, Mark começa a agir por meio da linguagem, usando a mentira (seu poder que o faz superior), para tornar as relações sociais mais harmônicas.

Isso também fica indiciado na conversa que Mark teve com sua mãe no leito de morte. Vejamos:

Martha (mãe de Mark): Estou com medo, Mark! As pessoas não comentam, mas a morte é uma coisa horrível! Num minuto, você está viva e, depois, é como se tudo sumisse. É o fim, Mark! Mais algumas horas assim e, depois, uma eternidade de vazio... Estou tão apavorada!

Mark: Mãe... Mãe, escuta aqui, com bastante atenção. Está enganada a respeito do que há depois da morte. Não é uma eternidade de vazio. Você visita seus lugares favoritos no mundo e todo mundo que a senhora já gostou vai estar lá. Vai voltar a ser jovem. Vai correr e pular como costumava... e dançar! A senhora 
dançava! Não terá mais dor. Só amor! Felicidade e todos ganham uma mansão e dura para toda a eternidade, mãe. Dá um oi no papai pra mim. Diz que eu o amo!

Por meio de um processo de reflexão e refração (BAKHTIN/VOLOCHINOV, 2006 [1929]) do discurso social de cunho religioso, a promessa do paraíso de algumas religiões cristãs, a personagem Mark, mais uma vez, usa seu poder (a mentira) para amenizar uma situação difícil.

Assim, diante das análises dos excertos-dizeres deste segundo momento do filme, é possível afirmar que o filme indicia que a mentira seria um elemento necessário ao bem-estar e conforto das pessoas. Por isso, podemos dizer que, nesse segundo momento do filme, o discurso da mentira que se evidencia é de que ela é um elemento necessário para o conforto e bem-estar individual.

Por fim, passemos à análise dos excertos do terceiro período do filme.

2.3 Carnavalização e mentira: terceiro momento - a necessidade de verdade para as relações amorosas

No último momento, o protagonista, frente a uma situação na qual ele poderia usar a mentira para conquistar a garota pela qual ele está interessado, opta por não mentir, pois, segundo ele, conseguir o amor dela por meio de uma mentira não seria válido.

Vejamos, no diálogo a seguir, a materialização desse discurso de que o amor só é válido se for verdadeiro:

Mark: O que você vê quando olha para mim?

Anna: Você é gordinho e tem nariz de batata.

Mark: É! Não passa disso!

Anna: ...é inteligente! Você é gentil! O homem mais interessante que eu já conheci, e é divertido estar com você. E você vê o mundo de um jeito que mais ninguém vê, e eu gosto do jeito que você vê o mundo. E você é meu melhor amigo. Me faz mais feliz que qualquer outra pessoa já fez! [...]

Mark: Por que não podemos ficar juntos?

Anna: Por causa do lance da genética: filhos gordinhos com nariz de batata [...] É uma pena que ser rico e famoso não modifica a sua genética, porque eu te amo! Ser rico e famoso modifica sua carga genética?

Mark: Não! Não muda! Nossos filhos seriam gordinhos com nariz de batata. 
Por meio desse diálogo, percebemos o reflexo e a refração de diferentes discursos sociais (BAKHTIN/VOLOCHINOV, 2006 [1929]), tais como o da supervalorização da aparência em detrimento da personalidade e o de que o amor tem que ser de verdade. Ao retratar situação na qual esses discursos tomam forma, mais uma vez, percebemos indícios do fenômeno da carnavalização (BAKHTIN, 2015). Ou seja, a superioridade conferida ao protagonista, por meio da mentira, desfaz-se diante de uma situação da qual ele poderia tirar proveito próprio: "o rei é destronado".

No excerto-diálogo abaixo, percebemos mais uma vez a materialização do discurso de que o amor só é válido quando é de verdade, refletindo e refratando (BAKHTIN/VOLOCHINOV, 2006 [1929]) um discurso social sobre o amor (SANTOS, 2015):

\footnotetext{
Anna: Por que não me diz o que o homem do céu quer?

Mark: Eu fiz uma coisa errada.

Anna: Tudo bem, pode fazer três.
}

Mark: Não, você não entendeu! Eu... Não existe nenhum homem no céu.

Anna: Por que disse que existia?

Mark: Eu não pude suportar o olhar da minha mãe ao morrer, e a situação foi se agravando.

Anna: Mas como você disse uma coisa que não era?

Mark: Eu não sei! Dizendo! Eu consigo.

Anna: Mas quando eu perguntei se ser rico, bem-sucedido e famoso mudava a sua genética, por que não disse que sim?

Mark: Porque assim não vale!

Nesse terceiro período, temos indícios de que o discurso sobre a mentira que se faz presente é o de que nem sempre compensa usar a mentira em benefício próprio, pois há coisas que só valem à pena se forem de verdade, como, por exemplo, o amor.

Assim, com esse terceiro momento do filme, percebemos a concretização da carnavalização na obra ficcional, pois o protagonista que era visto como um "bobo", a partir do momento que adquire a capacidade de mentir (seu "poder"), torna-se uma pessoa destacada, um "rei". No entanto, diante da situação que envolve o amor, o "rei" é destronado, pois não acredita que o amor só vale se for de verdade. Eis uma das características que permite enquadrar a obra ficcional como sendo de natureza 
carnavalesca: a personagem principal é posta em um trono e, em seguida, destronada.

\section{Considerações finais}

Neste trabalho, buscamos, por meio da análise de excertos-dizeres do filme $O$ primeiro Mentiroso, de Ricky Gervais e Matthew Robinson, analisar como o discurso da mentira é retratado no filme. Para tanto, lançamos mão da teoria bakhtiniana de linguagem e, mais especificamente, das noções de marcas dialógicas-ideológicas e do conceito de carnavalização. A partir disso, podemos proceder à analise de como a realidade social é refletida e refratada por meio da obra ficcional, evidenciando discursos sobre a mentira.

Feito isso, percebemos que a criação ficcional, que se dá por meio de um ato/acontecimento estético (BAKHTIN, 2011a [1920/30]), traz, em si, por meio de relações de diálogo e/ou tensão, reflexos e refrações sociais que corroboram a afirmação de três diferentes discursos sobre a mentira: no primeiro momento, por meio da narração de situações sociais pautadas unicamente na verdade, sobressai um discurso da mentira como algo necessário para a boa e cordial relação entre indivíduos; no segundo momento, por meio da mostra de como a mentira pode tornar situações difíceis mais fáceis, temos o discurso de que a mentira pode ser importante para a harmonização e bem-estar de situações difíceis; e, por fim, no terceiro período, por meio da recusa do uso da mentira para conseguir o amor da mulher pela qual o protagonista estava apaixonado, percebemos um discurso de que nem sempre a mentira compensa.

Assim, por meio da análise da criação ficcional, percebemos uma ideologização dos dizeres que refletem e refratam as relações sociais (BAKHTIN/VOLOCHINOV, 2006 [1929]; SANTOS, 2015), ainda que, sendo um ato/acontecimento estético, de forma carnavalizada.

\section{Referências}

BAKHTIN. M. Para uma filosofia do ato responsável. Tradução do italiano de Valdemir Miotello e Carlos Alberto Faraco. São Carlos, SP: Pedro \& João Editores, 2010 [1919/20]. 
BAKHTIN. M. O autor e a personagem na atividade estética. In: BAKHTIN, M. Estética da criação verbal. Introdução e tradução de Paulo Bezerra. 6. ed. São Paulo: Martins Fontes, 2011a [1920/30], p. 23-220.

BAKHTIN. M. O discurso no romance. In: BAKHTIN, M. Questões de literatura e estética. São Paulo: Editora Unesp, 1998 [1934/35], p. 71-210.

BAKHTIN. M. Os gêneros do discurso. In: BAKHTIN, M. Estética da Criação Verbal. Introdução e tradução de Paulo Bezerra. 6. ed. São Paulo: Editora WMF Martins Fontes, 2011b [1952/53], p. 261-306

BAKHTIN. M. Problemas da Poética de Dostoiévski. Tradução, notas e prefácio de Paulo Bezerra. 5. ed. Rio de janeiro: Forense Universitária, 2015.

BAKHTIN. M./VOLOCHINOV, V. Marxismo e filosofia da linguagem: problemas fundamentais do método sociológico na ciência da linguagem. 12. ed. São Paulo: Hucitec, 2006 [1929].

FANINI, A. M. R. Embate dialógico entre leitura e escrita: Manifestação de uma ética da ação discursiva a partir do Círculo Bakhtiniano. Bakhtiniana, São Paulo, 10 (2): 17-35, maio/ago. 2015. Disponível em: <http://dx.doi.org/10.1590/2176-457322177>. Acesso em: 15 jun. 2017.

SANTOS, A. C. Linguagem e construção de sentido: o dialogismo como característica base da interação verbal. Odisseia, Natal, RN, n. 15, p. 18-30, jul.dez. 2015. Disponível em: <https://periodicos.ufrn.br/odisseia/article/view/9585/ 7227>. Acesso em: 15 jun. 2017.

VOLOCHINOV, V. Que é a linguagem?. 2013 [1930a]. In: VOLOCHINOV, V. A construção da enunciação e outros ensaios. Tradução de João Wanderley Geraldi. São Carlos, SP: Pedro \& João editores, 2013, p. 131-156.

VOLOCHINOV, V. A construção da enunciação. [1930b] 2013. In: VOLOCHINOV, V. A construção da enunciação e outros ensaios. Tradução de João Wanderley Geraldi. São Carlos, SP: Pedro \& João editores, 2013, p. 157-188. 